PS-014

MEASUREMENT OF TISSUE-DOPPLER-DERIVED STRAIN AND STRAIN RATE IN VERY LOW BIRTH WEIGHT PRETERM INFANTS WITHIN THE FIRST 28 DAYS OF LIFE

${ }^{1} \mathrm{~S}$ Helfer, ${ }^{1} \mathrm{~L}$ Schmitz, ${ }^{2} \mathrm{C}$ Bührer, ${ }^{2} \mathrm{C}$ Czernik. ${ }^{1}$ Department of Pediatric Cardiology, Charité University Medical Centre, Berlin, Germany; ${ }^{2}$ Department of Neonatology, Charité University Medical Centre, Berlin, Germany

10.1136/archdischild-2014-307384.310

Background Preterm infants and especially very low birth weight (VLBW) preterms are prone to suffer from cardial stress due to bronchopulmonary dysplasia (BPD) or hemodynamically significant patent ductus arteriosus (hsPDA). Tissue-Dopplerimaging (TDI) based strain and strain rate measurements are ultrasound techniques that so far have not been used to assess cardiac function in this population.

Aim of this study was to assess TDI based strain and strain rate by in VLBW infants and their correlations with the infants' clinical courses within the first 28 days of life.

Methods We conducted ultrasonic measurements on days 1, 7, 14 and 28 of life in 119 preterm infants with a birth weight below $1500 \mathrm{~g}$. We assessed peak systolic strain (PSS) and strain rate (PSSR) and compared these parameters depending on birth weight, weight at examination and heart rate as well as the presence of a PDA or development of BPD.

Results PSS and PSSR of only the right ventricle increased during the first 28 days of life. Infants with hsPDA showed significantly lower values for left wall PSS on days 14 that only increased insignificantly after closure of the PDA. Incipient BPD was associated with significantly lower PSS in the right wall on days 14 and 28 of life.

Discussion Although BPD and hsPDA are highly intercorrelated in VLBW preterms, we were able to show that increased afterload due to BPD and increased preload due to PDA are associated with decreased PSS. Benefits of clinical applications, however, remain to be assessed.

\section{PS-015 TISSUE DOPPLER ASSESSMENT OF MYOCARDIAL FUNCTION IN HYPOTENSIVE PRETERM INFANTS}

A Singh, SV Rasiah, RJS Negrine, AK Ewer. Neonatal Unit, Birmingham Women's NHS Foundation Trust, Birmingham, UK

\subsection{6/archdischild-2014-307384.311}

Background Sick preterm neonates may have significant cardiac dysfunction. Blood pressure (BP) may be a surrogate marker however mean BP alone does not indicate the nature of myocardial dysfunction.

Aim To analyse biventricular myocardial velocities and myocardial performance indices (MPI) using tissue Doppler imaging (TDI) in preterm neonates $<30$ weeks gestation, with and without hypotension, in the first $24 \mathrm{~h}$ of life.

Methods 25 preterm neonates were recruited: 15 were normotensive and 10 were hypotensive. The hypotensive group (HT) received between 1 and 5 interventions (fluid and inotropes) till they were normotensive. Peak systolic (S'), early diastolic (E'), late diastolic (A) myocardial velocities and MPIs from the lateral annulus of the left and right atrio-ventricular valves were measured. Scans were performed after each intervention.

Results The left ventricular (LV) MPI was significantly higher in the hypotensive group compared to the normotensive group ( $p$ $=0.01$ ) suggesting left ventricular dysfunction. Biventricular
MPIs decreased significantly when hypotension was corrected, indicating an improvement in myocardial function $(\mathrm{RV} p=$ 0.01 , LV p $=0.05)$. Trans-mitral E' also showed an improvement following intervention for HT suggesting improvement in left ventricular relaxation $(\mathrm{p}=0.02)$.

Conclusion Although our study is small we have demonstrated that hypotensive preterms have impaired left ventricular function. Myocardial function improved after intervention in the hypotensive group. More studies are needed to investigate the application of TDI as an adjunct in clinical decision making when managing preterm babies with hypotension.

\section{PS-016 EXCESSIVE LEFT VENTRICULAR MYOCARDIAL GROWTH DIRECTLY AFTER PRETERM BIRTH}

U Schubert. Neonatology, Karolinska Institute, Stockholm, Sweden

\subsection{6/archdischild-2014-307384.312}

Background and aims Early cardiac re-modelling in preterm animals and increased left ventricular mass (LVM) in young adults born preterm have been reported. We investigated LVM in infants for early adaptational myocardial changes during 6 months after preterm birth.

Method Longitudinal echocardiographic study measuring LVM in 25 preterm infants (GA 26-30) directly after birth, at term and 3 months post-term, and comparison to 30 age-matched term children after correction for body surface area $\left(\mathrm{m}^{2}\right)$.

Results $\mathrm{LVM} / \mathrm{m}^{2}$ increased with $78 \%$ during the first three months after preterm birth (37.43 to $66.73 \mathrm{~g} / \mathrm{m}^{2}$ ) compared to $13 \%$ in controls (49.39 to $55.70 \mathrm{~g} / \mathrm{m}^{2}$ ). At term, $\mathrm{LVM} / \mathrm{m}^{2}$ was significantly higher in the preterm group $\left(66.73\right.$ vs $49.39 \mathrm{~g} / \mathrm{m}^{2}$, $\mathrm{p}<0.001)$. Preterm infants developed even more absolute LVM (12.79 vs $10.79 \mathrm{~g}, \mathrm{p}=0.02)$ although they were slightly lighter (3.18 vs $3.45 \mathrm{~kg})$.

At three months of corrected age, relative LVM decreased, and no significant differences could be shown between the groups.

Conclusion Preterm infants develop an immediate but transient increase in LVM. Premature myocardial maturation, increased afterload and a narrower vascular tree might be responsible for left ventricular hypertrophy. The impact on short and long term left ventricular function is still unclear and has to be explored.

\section{PS-017 CHANGES IN TROPONIN-T AFTER EXTREMELY PRETERM BIRTH}

${ }^{1} \mathrm{~A}$ Gudmundsdottir, ${ }^{1} \mathrm{M}$ Bartocci, ${ }^{2} \mathrm{G}$ Printz, ${ }^{3} \mathrm{C}$ Attner, ${ }^{4} \mathrm{~K}$ Bohlin, ${ }^{1} \mathrm{~J}$ Ekström, ${ }^{5} \mathrm{M}$ Karlsson, ${ }^{1} \mathrm{AK}$ Bonamy. 'Department of Women's and Children's Health, Karolinska Institutet, Stockholm, Sweden; ${ }^{2}$ Neonatal Department, Karolinska University Hospital, Stockholm, Sweden; 'Sachs' Children's Hospital, Neonatal Department, Stockholm, Sweden ${ }^{4}$ Clinical Science Intervention and Technology, Karolinska Institutet, Stockholm, Sweden; ${ }^{5}$ SÖS, Karolinska Institutet, Stockholm, Sweden

\subsection{6/archdischild-2014-307384.313}

Background Cardiac Troponin-T (cTNT) has been proposed as a useful marker of PDA-severity in preterm infants. Longitudinaldata on cTNT in extremely preterm infants is scarce.

Methods We included 60 infants born before 28 weeks of gestation at the Karolinska University Hospital in Stockholm Sweden and measured cTnT at 3 days (range 2-4) and 7 days (range 59) of age. Fourty-two infants had cTNT measured at two weeks 